\title{
Pensamento Computacional e Cultura Digital: discussões sobre uma prática para o letramento digital
}

\author{
Júlia dos Santos Bathke Ortiz, Deógenes Silva Junior, \\ Carolina Moreira Oliveira, Roberto Pereira
}

Programa de Pós-Graduação em Informática (PPGInf)

Universidade Federal do Paraná (UFPR)

Curitiba - PR - Brasil

\{jubathke, dornyjunior, carolmoliveiraa\}@gmail.com, rpereira@inf.ufpr.br

\begin{abstract}
This paper discusses Computational Thinking as a way to promote Digital Culture. Focusing on socially challenged audiences and contexts, we argue that Computational Thinking skills and concepts (e.g., abstraction, pattern recognition, algorithms) contribute to understanding, using and appropriation of computing technology, requiring, however, a situated and inclusive approach. Exemplifying our discussion, we present an activity designed to promote digital literacy in the context of Adult Education, presenting the concepts of Computational Thinking approached and the results obtained.
\end{abstract}

Resumo. Este artigo apresenta uma discussão sobre Pensamento Computacional como uma forma de promover a constituição de Cultura Digital. Com foco em públicos de contextos socialmente desafiadores, argumentamos que as habilidades e conceitos do Pensamento Computacional (e.g., abstração, reconhecimento de padrões, algoritmos) contribuem para o entendimento, uso e apropriação de tecnologias computacionais, mas requerem uma abordagem contextualizada e inclusiva. Para exemplificar nossa discussão, apresentamos uma atividade concebida para apoiar o letramento digital no contexto da Educação de Jovens e Adultos, explicando os conceitos do Pensamento Computacional trabalhados e os resultados obtidos.

\section{Introdução}

Publicado pelo Centro de Inovação para a Educação Brasileira (CIEB), o Currículo de Referência em Tecnologia e Computação [Raabe et al. 2018] identifica três eixos para a Educação Infantil e para o Ensino Fundamental: 1. Pensamento Computacional entendido como a capacidade de sistematizar, representar, analisar e resolver problemas; 2. Tecnologia Digital - abrangendo os componentes físicos e virtuais que possibilitam que a informação seja codificada, organizada e recuperada; e 3. Cultura Digital — no qual relações da Computação com outras áreas são exploradas para promover a fluência no uso do conhecimento computacional de forma contextualizada e crítica, com destaque para o letramento e a cidadania digital. Como ilustrado pela Figura 1, os 3 eixos são subdivididos em 10 conceitos. Esses conceitos propõem o desenvolvimento de habilidades específicas que devem ser trabalhadas nas escolas.

Outras iniciativas, como [Council 2010] e [Barr e Stephenson 2011], também propõem habilidades e conceitos que devem ser trabalhados para promover o ensino de Tecnologia e Computação nas escolas. Embora tenham diferentes focos e abordagens, as 
VIII Congresso Brasileiro de Informática na Educação (CBIE 2019)

Anais do XXX Simpósio Brasileiro de Informática na Educação (SBIE 2019)

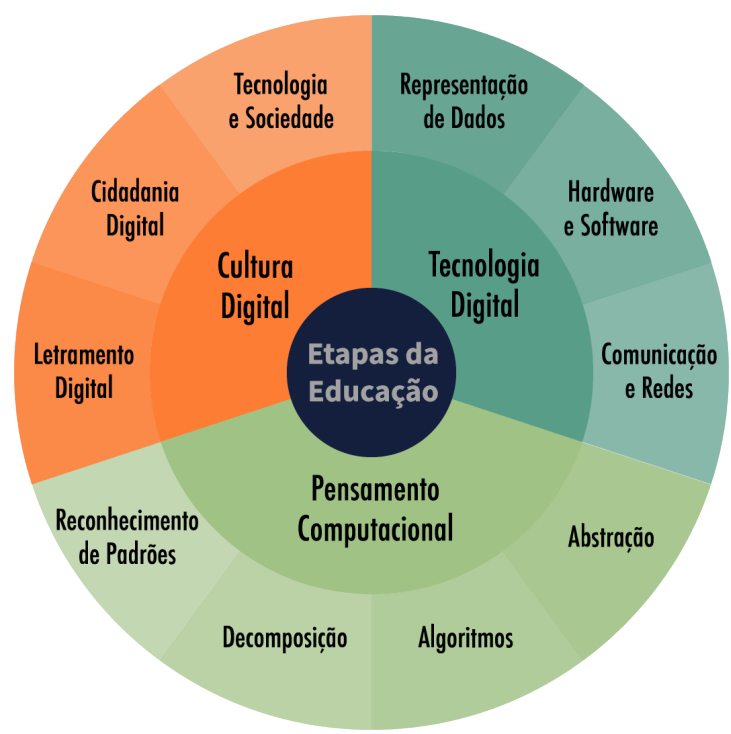

Figura 1. Eixos e Conceitos do Currículo CIEB [Raabe et al. 2018]

iniciativas normalmente destacam a importância do Pensamento Computacional no desenvolvimento da autonomia e de competências para a era digital, e tendem a focar nas modalidades do Ensino Básico e Ensino Médio. O Ensino Superior, embora com menos destaque, também tem sido foco de pesquisas e possui resultados sendo disseminados. Pouco se tem falado, investigado e feito sobre Pensamento Computacional no contexto de outros públicos, especialmente aqueles em situações de vulnerabilidade e de exclusão digital, econômica e social. De acordo com um mapeamento sistemático da literatura sobre iniciativas de ensino do Pensamento Computacional [Ortiz e Pereira 2018], de 2007 até 2017 apenas um artigo mapeado reportava resultados de iniciativa de desenvolvimento do Pensamento Computacional na Educação de Jovens e Adultos [Ortiz e Raabe 2016].

Se para crianças e adolescentes o Pensamento Computacional é uma habilidade importante para a vida na era digital, para as pessoas em situação de exclusão social e digital, o desenvolvimento dessa habilidade é uma questão de identidade e de existência para o exercício da cidadania. Entendemos que, quando o propósito de uma iniciativa for promover a autonomia e a inclusão, o Pensamento Computacional não deve ser entendido como um eixo junto aos de Tecnologia e Cultura Digital (Figura 1), mas como uma base que sustenta e promove o desenvolvimento de competências nesses eixos.

Neste artigo, entendemos o desenvolvimento de habilidades do Pensamento Computacional como um meio de promover a inclusão e a constituição de uma cultura digital. Nesse entendimento, o Pensamento Computacional possui uma relação de benefício mútuo com o uso de Tecnologias de Informação e Comunicação (TICs): ao mesmo tempo em que potencializa a autonomia no uso e apropriação de tecnologias, o Pensamento Computacional é desenvolvido e aprimorado com os resultados de uma experiência autônoma e positiva, em um ciclo de reforço contínuo.

Para desenvolver a discussão, apresentamos uma prática para promover o entendimento e uso de tecnologia na Educação de Jovens e Adultos, destacando os conceitos e habilidades relacionadas ao Pensamento Computacional que, em estágio inicial, favorecem a inclusão. Além de trazer uma perspectiva inclusiva para a importância do Pensamento 
VIII Congresso Brasileiro de Informática na Educação (CBIE 2019)

Anais do XXX Simpósio Brasileiro de Informática na Educação (SBIE 2019)

Computacional, o artigo contribui apresentando uma atividade que pode ser aplicada em outros contextos, junto com os principais resultados percebidos da sua aplicação.

\section{Contexto e Fundamentação}

Dentre os Grandes Desafios de Pesquisa em Computação no Brasil, o "Acesso Participativo e Universal do Cidadão Brasileiro ao Conhecimento" foi identificado como sendo essencial para o desenvolvimento social e econômico do país, favorecendo a inclusão social e digital e garantindo o acesso ao conhecimento e a recursos que possibilitem o exercício da cidadania [Baranauskas e De Souza 2006]. Enquanto habilidade de resolver problemas utilizando técnicas e fundamentos da Computação [Wing 2006], o Pensamento Computacional tem potencial de promover esse acesso participativo e universal à medida que contribui com o desenvolvimento de habilidades essenciais para o entendimento, uso e apropriação das TICs, como aquelas relacionadas aos conceitos da Figura 1.

Na Interação Humano-Computador, o conceito de Modelos Mentais tem sido explorado e discutido desde a década de 80. Norman (1988) chama de modelo mental os modelos que as pessoas possuem delas mesmas, dos outros, do ambiente e das coisas com as quais elas interagem, explicando que modelos são construídos pela experiência, treinamento e instrução. Preece et al. (1994) expõem que, do mesmo modo que um engenheiro produz um modelo de uma ponte para testar e experimentar possibilidades antes de construí-la efetivamente, nós construímos modelos mentais do mundo para fazermos predições sobre um evento externo antes de executar uma ação.

O conhecimento geral produzido na interação com o mundo é armazenado na forma de esquemas que, ao serem ativados, podem ser usados para construir modelos mentais. Preece et al. (1994) destacam que as pessoas desenvolvem dois tipos de modelos úteis para o entendimento e uso de dispositivos e sistemas: modelos estruturais que descrevem como dispositivos ou sistemas funcionam e modelos funcionais que descrevem como usar um dispositivo ou sistema.

A maior parte do entendimento que as pessoas produzem sobre dispositivos e sistemas é funcional e dependente do contexto. A interação com (e por meio de) TICs é favorecida quando se possui um modelo mental adequado sobre a tecnologia, como ela funciona (estrutural), suas possibilidades e restrições de uso (funcional). Por promover o desenvolvimento de habilidades como abstração, reconhecimento de padrões e algoritmos, o Pensamento Computacional tem potencial de proporcionar a formação de modelos mentais úteis e significativos tanto para o uso de tecnologias - favorecendo os conceitos do letramento digital, quanto para atividades técnicas mais elaboradas - favorecendo os conceitos da tecnologia digital.

Além das habilidades e conceitos relacionados ao Pensamento Computacional, a construção de bons modelos mentais é influenciada pela experiência prévia e continuada das pessoas com um local, situação ou objeto, assim como pelo interesse, afinidade e motivação que a pessoa desenvolve para interagir com a tecnologia. Em artigo publicado na Communications of the ACM [Tissenbaum et al. 2019], os autores defendem um movimento de mudança do Pensamento Computacional para a ação computacional, enfatizando a necessidade das pessoas se verem capazes de conceber soluções para seus problemas reais. Citando Paulo Freire e Seymour Papert, os autores argumentam que é preciso focar em experiências significativas e importantes para o con- 
VIII Congresso Brasileiro de Informática na Educação (CBIE 2019)

Anais do XXX Simpósio Brasileiro de Informática na Educação (SBIE 2019)

texto de vida dos alunos, favorecendo a construção de soluções como meio de construir conhecimento de forma relevante e socialmente situada - algo que pesquisadores brasileiros como Baranauskas e Valente já defendem e praticam há mais de três décadas [Valente 1993, Valente et al. 2014, Baranauskas e Carbajal 2017].

Para públicos em situação desafiadora e marcada pela exclusão, antes da questão do desenvolvimento de habilidades do Pensamento Computacional e da construção de bons modelos mentais, há desafios de natureza social-cultural-econômica que levantam barreiras ao contato com as tecnologias. Barreiras tão fortes que também são internalizadas na ideia de que "isso [a tecnologia] não é pra mim". Para esses públicos, o ponto de partida é conseguir engajar as pessoas em experiências significativas e positivas com o uso de TICs, em dinâmicas que promovam o bem-estar e o sentido de pertencimento. É preciso desenvolver um entendimento situado no contexto a ser trabalhado, conhecendo as pessoas, suas necessidades, expectativas, valores, dificuldades e motivações; é preciso conhecer a realidade socioeconômica, os recursos disponíveis e a linguagem não verbal da interação cotidiana. Com esse engajamento, é possível pensar, planejar e conduzir ações que promovam o desenvolvimento de habilidades do Pensamento Computacional. Essas ações devem apoiar a construção de modelos mentais úteis para o uso e apropriação de tecnologias, e que ajudem na constituição de uma cultura digital que incorpora o letramento digital e o exercício da cidadania de formas socialmente responsáveis.

Pensar e conduzir ações para promover o desenvolvimento de habilidades do Pensamento Computacional como meio para a constituição da cultura digital é uma tarefa desafiadora. Por um lado, o caráter situado e único de cada contexto de atuação torna difícil replicar práticas bem-sucedidas e não é compatível com a adoção de soluções prontas, concebidas para outras realidades. Por outro lado, há princípios que guiam e fundamentam a prática e a postura de seus participantes, e lições aprendidas que podem apoiar e inspirar o trabalho em outros contextos. Na próxima seção, apresentamos um exemplo prático de uma atividade conduzida com alunos da Educação de Jovens e Adultos, detalhando a atividade, caracterizando sua aplicação e discutindo seus resultados.

\section{Pensamento Computacional e Letramento Digital na Prática}

Em uma iniciativa para promover a inclusão e a constituição da cultura digital, um conjunto de atividades foi conduzido com alunos da Educação de Jovens e Adultos da Escola Municipal Rachel Mader Gonçalves. Anteriormente ao início dos encontros para as atividades, sabíamos que: os alunos estavam em fase de alfabetização, possuíam contato raro com TICs, vinham de contextos de vida difíceis, a frequência e a pontualidade oscilavam bastante, possuíam diferentes limitações mas nenhuma deficiência em nível severo (e.g., cegueira ou surdez), e era contínuo o esforço das professoras para o envolvimento e dedicação dos alunos.

O conjunto de encontros representou uma "Temporada" dedicada à aproximação dos alunos com as TICs que já permeiam a nossa vida em sociedade. A temporada buscou desconstruir a vergonha, o medo, a resistência ou a rejeição ao contato com as tecnologias, e a percepção sobre a tecnologia ser algo distante e que não lhes era de direito conhecer. Assim, as atividades foram planejadas para: conhecer o público-alvo e mostrar que, juntos de forma colaborativa e continuada, todos têm condições de aprender sobre e como utilizar a tecnologia. Todas as atividades foram pautadas na ideia de que a tecnologia 
VIII Congresso Brasileiro de Informática na Educação (CBIE 2019)

Anais do XXX Simpósio Brasileiro de Informática na Educação (SBIE 2019)

pode (e deve) ser para todos, mesmo com as dificuldades e possibilidades individuais. Do ponto de vista de Pensamento Computacional, as atividades possibilitaram trabalhar as habilidades de algoritmos, análise de dados, reconhecimento de padrões, decomposição de problemas, simulação e automação em situações cotidianas, com e sem o uso de tecnologias, conversando sobre elas, para que servem, etc.

Em nossas atividades, assumimos que, ao aprender os passos para tirar uma foto ou para fazer uma busca específica via comando de voz, por exemplo, as pessoas vão desenvolvendo habilidades de pensamento algorítmico; e que quando executam essas atividades repetidamente, em diferentes dispositivos e aplicativos, vão desenvolvendo habilidades de reconhecimento de padrões e abstração, entre outras habilidades. Nesse entendimento, em níveis básicos, as habilidades do Pensamento Computacional são promissoras para promover a constituição da cultura digital; em níveis intermediários, favorecem a apropriação e autonomia no uso da tecnologia de acordo com as preferências e necessidades de seus usuários; e em níveis avançados, são características de profissionais e entusiastas que criam novas tecnologias e modificam as existentes.

A atividade apresentada nesta seção foi planejada e conduzida por 3 facilitadores, todos pesquisadores em Interação Humano-Computador e Informática na Educação. A atividade teve duração de aproximadamente 2 horas e contou com a participação de 12 alunos da Educação de Jovens e Adultos (10 mulheres, 2 homens) com idades entre $21 \mathrm{e}$ 70 anos. Em atividades anteriores, que incluíram uma dinâmica baseada em StoryTelling, os alunos mencionaram possuir parentes que moram longe, com quem falam pelo celular, mas somente quando alguma outra pessoa realiza ou atende a ligação por eles. Eles mesmos nunca haviam realizado uma chamada.Como o aplicativo WhatsApp era popular e já havia sido discutido com os alunos em encontros anteriores, a atividade foi conduzida para apresentar uma sequência de passos para realizar ligações de áudio e vídeo por meio do aplicativo em uma experiência colaborativa.

\subsection{Conhecendo o WhatsApp e Fazendo Ligações}

Com o objetivo de apresentar o aplicativo WhatsApp e conhecer um conjunto de passos para realizar uma ligação por vídeo, foram apresentados aos participantes elementos gráficos e uma "receita" com os ícones e símbolos para realizar a tarefa.

Materiais: Impressões com o símbolo do WhatsApp; símbolo da chamada de áudio no WhatsApp e a imagem de um telefone antigo; símbolo da chamada de vídeo no WhatsApp e a imagem de uma filmadora antiga (Figura 2); impressões em tamanho real das telas do celular para simular a execução das ligações de áudio e vídeo (Figura 3); sequência de passos representada de forma pictórica para a realização de chamadas por meio do aplicativo; celulares com conexão à Internet.

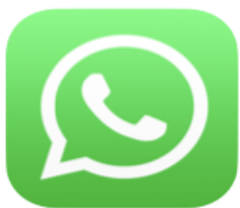

(a)

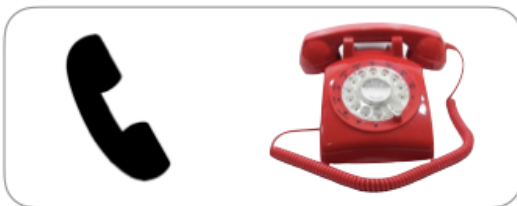

(b)

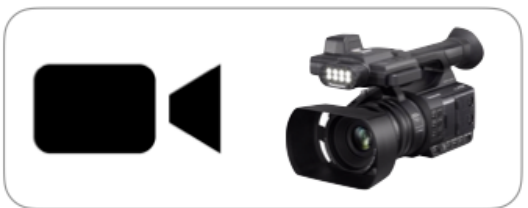

(c)

Figura 2. Figuras do WhatsApp, telefone e filmadora 
VIII Congresso Brasileiro de Informática na Educação (CBIE 2019)

Anais do XXX Simpósio Brasileiro de Informática na Educação (SBIE 2019)
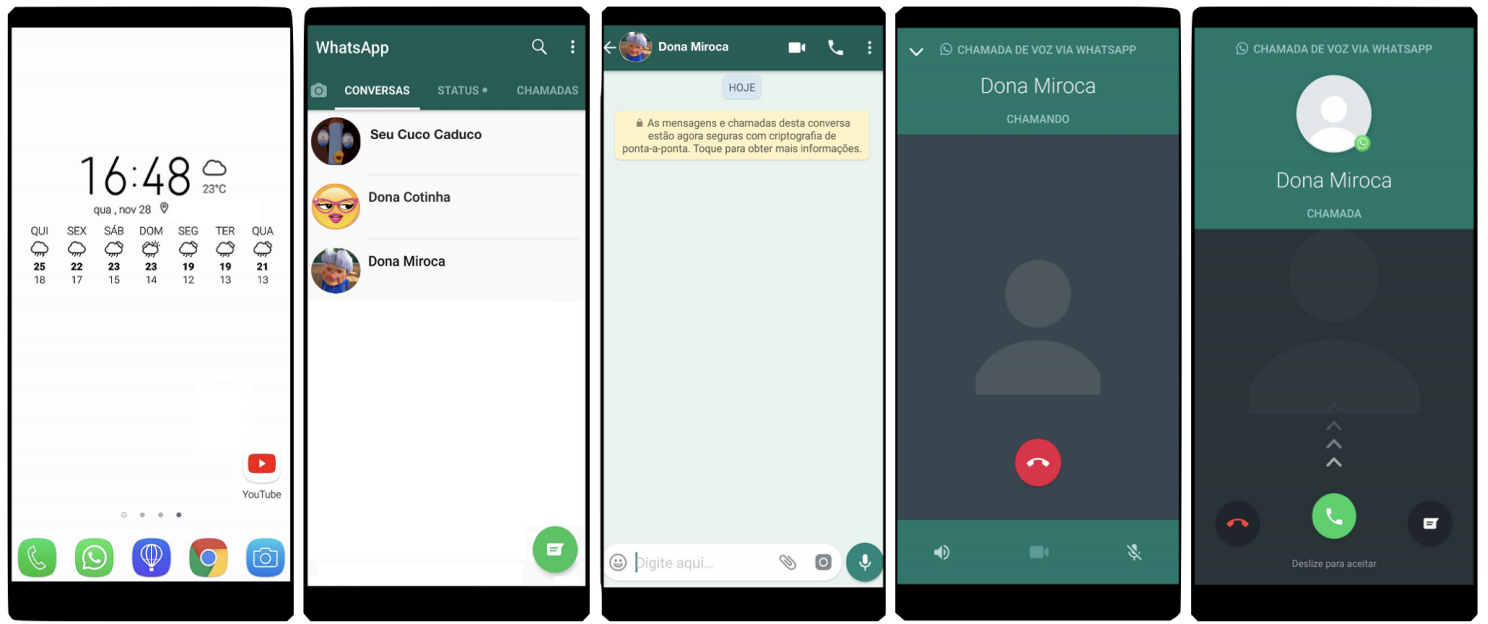

Figura 3. Telas do celular impressas para simulação das ligações

Método para a condução da atividade: 1. Apresentar o símbolo do WhatsApp, explicar seu significado e função em diferentes contextos, como no próprio celular, em panfletos, carros, etc. 2. Discutir a origem do símbolo, relacionando-o aos telefones residenciais antigos como uma forma de criar referências para a memorização. 3. Explicar que o ícone do telefone representa algum tipo de contato por meio de mensagem de texto no aplicativo ou por meio de ligação de voz. 4. Fazer a mesma relação com o símbolo de chamadas de vídeo, relacionando-o a um aparelho utilizado antigamente, a filmadora.

Após a discussão sobre a origem dos ícones, pode-se avançar para o exercício de fazer ligações: 5. Dividir o grupo de participante em, pelo menos, dois grupos (A e B) de aproximadamente a mesma quantidade de pessoas e posicionar os grupos em partes diferentes da sala (idealmente, em salas diferentes). 6. Entregar a cada grupo a sequência de passos pictórica (Figura 4) indicando como fazer uma ligação de áudio/vídeo no WhatsApp em que os passos são:

- Abrir o WhatsApp;

- Escolher a pessoa para quem deseja ligar (com o auxílio das fotografias);

- Tocar no "desenho" para fazer a chamada de áudio/vídeo.

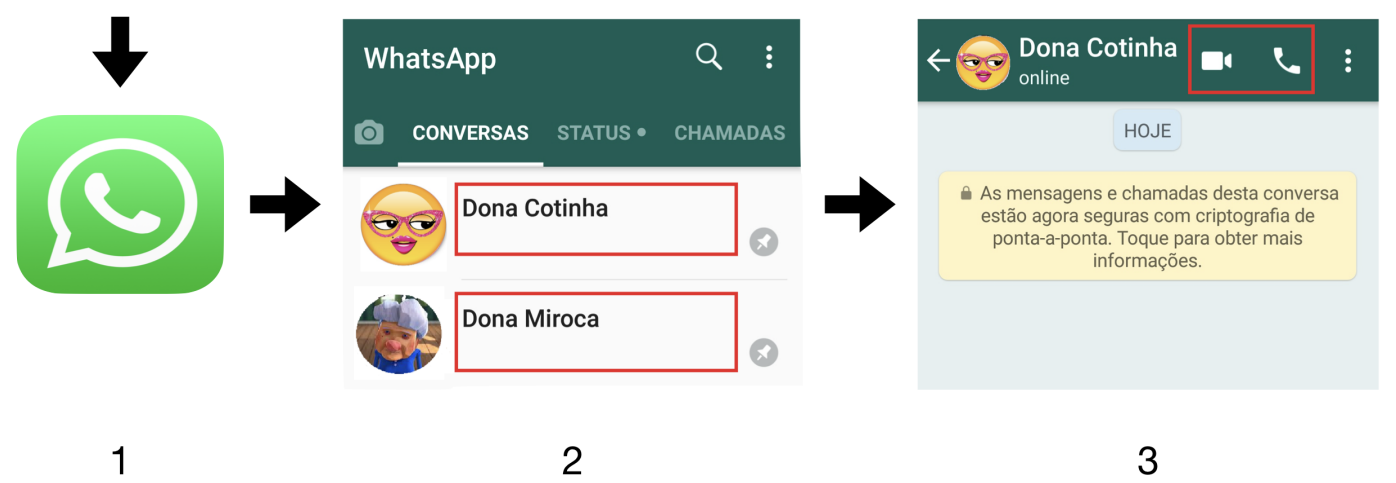

Figura 4. Sequência de passos pictórica para realizar chamadas no WhatsApp

Ao executar a sequência de passos: 7. uma pessoa do Grupo A ligará para outra do Grupo B, que deverá atender. Idealmente, a comunicação entre os alunos durante a 
VIII Congresso Brasileiro de Informática na Educação (CBIE 2019)

Anais do XXX Simpósio Brasileiro de Informática na Educação (SBIE 2019)

ligação deve envolver algum conteúdo significativo para todos. Por exemplo, em nossa atividade prática, como os alunos haviam assistido a um filme no qual a personagem principal sempre falava rimando todas as palavras, a pessoa que ligou deveria falar uma palavra e a pessoa que recebeu a ligação deveria responder com outra palavra que rimasse com a palavra ouvida; na sequência, a pessoa do Grupo B que atendeu a ligação deveria fazer uma ligação ao Grupo A, e outro aluno deveria atender, sucessivamente até que todos tivessem ligado e atendido uma ligação.

Ao final da atividade, os alunos terão praticado ligações de áudio e vídeo, tanto realizando a chamada quanto atendendo. Os alunos também terão praticado as habilidades em nível básico de algoritmos, automação e reconhecimento de padrões por meio da interpretação e execução da lista ordenada de passos.

\subsection{Formas de Avaliação da Prática}

Embora sejam relacionados, em atividades que possuem o propósito de promover a cultura digital, a inclusão, o engajamento e o interesse dos participantes são mais importantes do que o progresso do aprendizado. Portanto, a satisfação com a experiência, a interatividade e o interesse em continuar participando e explorando novas tecnologias são aspectos que indicam se as atividades estão atingindo seu propósito. Esses aspectos podem ser identificados por meio do feedback explícito dos participantes ou por meio de observações dos pesquisadores e dados coletados durantes as práticas.

Para a atividade apresentada nesta seção, o ponto crucial é identificar a percepção dos participantes sobre o quanto aprenderam com a prática e se querem continuar aprendendo mais sobre tecnologias. Também é importante observar se todos os participantes executaram as atividades, se demonstraram interesse em acompanhar enquanto outros executavam, e se alguma manifestação positiva ou negativa ocorreu durante todo o processo. Os materiais para a avaliação podem ser: uma urna para votação, cartões verdes, amarelos e vermelhos, representando respostas ("sim", "mais ou menos" e "não", respectivamente) para alguma questão; cartões com carinhas, representando: sorrindo muito, sorrindo, neutra, triste e muito triste; formulário de observações com os aspectos a serem anotados durante a prática.

Ao término da atividade, deve-se perguntar aos participantes o quanto eles acham que aprenderam com a atividade de que participaram, orientando-os a selecionar um cartão que corresponda à sua opinião: cartão com carinha sorrindo muito ("aprendi muito"); sorrindo ("aprendi"); neutra ("estou com dúvidas" ou "não sei"); triste ("aprendi pouco"); e muito triste ("não aprendi nada"). Após a pergunta aos participantes, finalizar o encontro e agradecer a participação. A urna para depósito dos cartões deve ficar na saída da sala para que os participantes não se sintam envergonhados ou pressionados a votar.

\subsection{Resultados e Discussões}

A atividade foi conduzida em Novembro de 2018, com aproximadamente 2 horas de duração, seguindo a estrutura apresentada anteriormente. O ponto de partida para a atividade foi uma explicação sobre os ícones, símbolos e suas funcionalidades, e uma discussão com os participantes sobre a utilidade do aplicativo. Após a discussão, a atividade de ligação foi conduzida e todos os 12 participantes efetuaram e receberam pelo menos uma chamada. Após a finalização da atividade os alunos realizaram a votação utilizando os cartões. A Figura 5 mostra fotografias da execução da atividade com os alunos. 


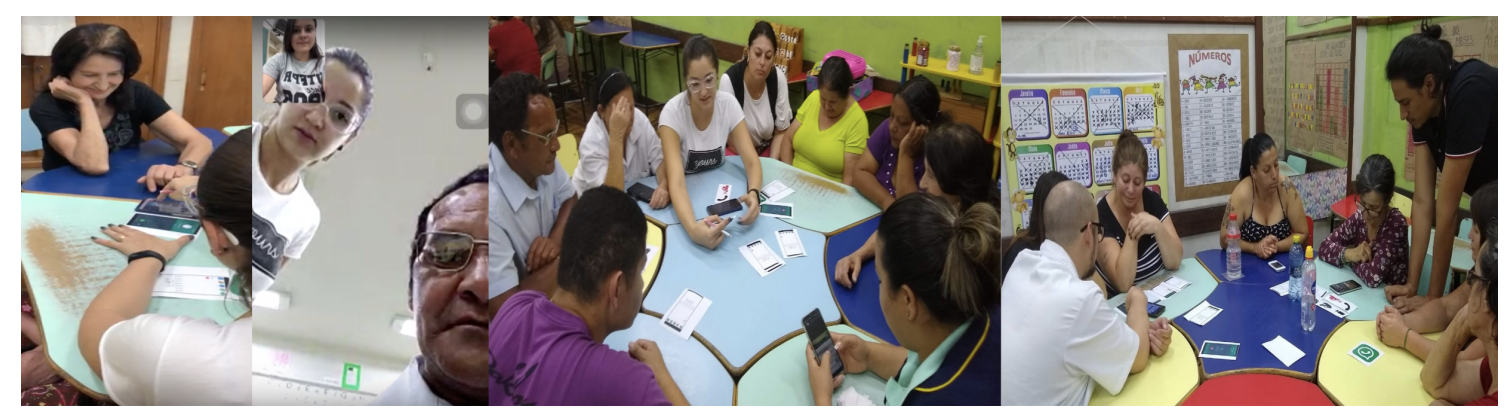

Figura 5. Fotografias da atividade

O celular e as ligações já faziam parte do dia a dia dos participantes, especialmente por causa de seus familiares. Porém, os alunos não conseguiam realizar as ligações de forma autônoma e não usavam o celular. Foi possível observar que os alunos estavam motivados em participar. Todos queriam fazer a atividade e traziam perguntas, provavelmente de situações que eles já vivenciaram. Consideramos que trazer várias telas de telefone impressas foi bastante positivo pois todos os alunos tinham em suas mãos um material para analisar as semelhanças e diferenças, para rabiscar, para fazer sentido, para treinar e para, posteriormente, aplicarem diretamente no celular. Além disso, pelo tamanho das telas ser semelhante ao real e por termos aumentado o tamanho da fonte nos celulares, todos os alunos conseguiram enxergar com facilidade.

A nossa percepção a respeito do engajamento e do êxito dos alunos na execução da tarefa foi positiva, pois todos se envolveram e conseguiram realizá-la. A postura dos alunos foi de curiosidade e expectativa para tentar realizar as ligações, e alguns exercitaram habilidades de simulação ao tentar executar passos da sequência sozinhos, se baseando somente nas telas impressas.

O resultado da votação para a pergunta "Quanto eu considero que aprendi na aula de hoje?" demonstra que os participantes tiveram uma excelente percepção de aprendizado e progresso: com 12 participantes na atividade, os 12 cartões selecionados foram cartões com uma carinha sorrindo muito, que indica "aprendi muito".

Nesta atividade, foram exercitadas as habilidades de algoritmos, por meio da interpretação, execução e depuração da solução (a própria sequência de passos); o reconhecimento de padrões, para reconhecer ícones e botões nas impressões e nos diferentes celulares utilizados na prática; e a automação, por eles mesmos terem executado a sequência de passos. Não descrevemos a sequência de passos, apenas disponibilizamos e explicamos como executar cada passo. A simulação também foi envolvida, pois embora os participantes estivessem utilizando dispositivos reais, antes de executar a ligação eles estavam simulando por meio das telas impressas o cenário de ligarem para parentes, amigos, etc.

Sobre a habilidade de algoritmos trabalhada explicitamente nesta atividade, pudemos observar que os alunos assimilaram algumas das características e benefícios dessa forma de pensar quando a relacionamos a uma receita, ou lista de passos, algo mais próximo do contexto deles. Todos tiveram histórias para contar sobre quando trocaram ou esqueceram de algum ingrediente na preparação de uma receita. Também compartilharam e compararam diferenças nos passos e materiais utilizados. 
VIII Congresso Brasileiro de Informática na Educação (CBIE 2019)

Anais do XXX Simpósio Brasileiro de Informática na Educação (SBIE 2019)

A atividade apresentada neste artigo foi a última de uma série de 7 atividades conduzidas semanalmente. Segundo relato das professoras, após as atividades, os alunos passaram a pedir a lista de passos/instruções do que precisava ser feito nas atividades, alegando que tinham que anotar para não esquecer como fazer e para poder consultar caso precisassem. Isso indica que os alunos absorveram a estratégia e passaram a aplicá-la em outros contextos. No que diz respeito a redução da barreira no contato e uso da tecnologia, as professoras reportaram que vários alunos comentaram que, agora, têm celular, pois ganharam de presente ou compraram, e que estão ansiosos por uma nova temporada de encontros para fazer novas atividades, agora usando os próprios celulares.

Ao conduzir esta atividade, sentimos a confiança nos alunos de que eles haviam compreendido como deveriam interpretar aquela sequência de passos, e que eles já não se colocavam mais na posição de não saber fazer o que estava sendo proposto: eles apenas não tinham feito ainda. Em um relato específico, uma aluna contou que, quando convidamos para as atividades, ela achou que não conseguiria participar e realizar nenhuma das atividades. Porém, quando ela tirou a primeira foto em uma prática conduzida no segundo encontro, ela decidiu que não iria mais parar de aprender sobre tecnologia. E, de fato, tirou várias fotos do Natal para mostrar às suas professoras e, agora, fotografa e mostra cada mudança que faz em sua horta. Outra aluna comentou que agora "mexe" direto no YouTube para procurar músicas e que conseguiu falar com o neto por meio de ligação de vídeo no WhatsApp; também contou que tirou fotos da família no fim de semana: os parentes acharam que ela não ia conseguir, mas ela conseguiu: "Perguntaram onde eu tinha aprendido. Aprendi na escola!" disse ela.

\section{Conclusão}

Neste artigo, discutimos que as habilidades do Pensamento Computacional possuem relação direta com a inclusão e o uso de tecnologias: ao mesmo tempo em que o Pensamento Computacional potencializa a autonomia e a apropriação de tecnologias, ele é desenvolvido e aprimorado com os resultados de uma experiência autônoma e positiva. O pontochave para que essa relação ocorra e se mantenha é o modo como as experiências são pensadas e conduzidas.

Para exemplificar nossa discussão, apresentamos uma prática planejada para exercitar o entendimento e execução de passos para realizar e receber ligações no aplicativo WhatsApp. Diferentes habilidades do Pensamento Computacional, como algoritmos e reconhecimento de padrões, foram exercitadas em uma atividade significativa para o contexto dos alunos, sendo um meio de reduzir a resistência e as barreiras ao contato com Tecnologias de Informação e Comunicação, favorecendo o letramento digital.

Ao final da atividade, os alunos mostraram excelente percepção de aprendizado, considerando que aprenderam muito com a prática. Essa auto-percepção é essencial ao trabalharmos com um público vulnerável ao abandono escolar, como o caso dos alunos da Educação de Jovens e Adultos. Para esse público, mais importante que uma métrica de aprendizado ou desempenho, é a percepção dos alunos sobre o próprio progresso, e a motivação e interesse dos mesmos em continuar participando e aprendendo.

Com atividades que promovam a identificação, organização e execução de passos para um determinado fim, como tirar uma foto ou encontrar um vídeo no YouTube usando comando de voz, interagindo com diferentes dispositivos e interfaces, entendemos que os 
VIII Congresso Brasileiro de Informática na Educação (CBIE 2019)

Anais do XXX Simpósio Brasileiro de Informática na Educação (SBIE 2019)

participantes exercitam as habilidades do Pensamento Computacional mesmo que em nível mais básico. Essas habilidades favorecem a construção de modelos mentais úteis para identificar como a tecnologia pode ser utilizada, favorecendo a literacia digital e a constituição da cultura digital. Investigar se é possível evoluir as habilidades do Pensamento Computacional de forma construtiva e contínua, favorecendo a inclusão, autonomia e a apropriação no uso de tecnologias, é um espaço de pesquisa que demanda estudos de caso de longa duração e exigem uma pesquisa participativa em parceria com alunos e professores.

\section{Agradecimentos}

Os autores agradecem pela parceria os alunos, alunas e professoras da Educação de Jovens e Adultos da Escola Municipal Rachel Mader Gonçalves. Pesquisa parcialmente apoiada pela Coordenação de Aperfeiçoamento de Pessoal de Nível Superior (CAPES) - Código de Financiamento 001.

\section{Referências}

Baranauskas, M. C. C. e Carbajal, M. L. (2017). The Social Nature of Programming: Children and Fluency, volume 10272.

Baranauskas, M. C. C. e De Souza, C. S. (2006). Desafio 4: Acesso participativo e universal do cidadão brasileiro ao conhecimento. Computação Brasil, 23(7):7.

Barr, V. e Stephenson, C. (2011). Computational thinking to k-12: What is involved and what is the role of the computer science education community. In ACM Inroads, pages $48-54$.

Council, N. R. (2010). Report of a Workshop on the Scope and Nature of Computational Thinking. The National Academies Press.

Norman, D. A. (1988). The psychology of everyday things. Basic books.

Ortiz, J. B. e Raabe, A. (2016). Pensamento computacional na educaçao de jovens e adultos: Liçoes aprendidas. In Anais dos Workshops do V CBIE-Congresso Brasileiro de Informática na Educaçao, pages 1087-1096.

Ortiz, J. d. S. B. e Pereira, R. (2018). Um mapeamento sistemático sobre as iniciativas para promover o pensamento computacional. In Simpósio Brasileiro de Informática na Educação-SBIE, page 1093.

Preece, J., Rogers, Y., Sharp, H., Benyon, D., Holland, S., e Carey, T. (1994). Humancomputer interaction. Addison-Wesley Longman.

Raabe, A. L. A., Brackmann, C. P., e Campos, F. R. (2018). Currículo de referência em tecnologia e computação. CIEB.

Tissenbaum, M., Sheldon, J., e Abelson, H. (2019). From computational thinking to computational action. Communications of the ACM, 62(3):34-36.

Valente, J. A. (1993). Computadores e conhecimento: repensando a educação. Unicamp.

Valente, J. A., Baranauskas, M. C. C., e Martins, M. C. (2014). ABInv Aprendizagem Baseada na Investigação.

Wing, J. M. (2006). Computational thinking. Communications of the ACM, 49(3):33-35. 